\title{
Ascension Island shallow-water Zoantharia (Hexacorallia: Cnidaria) and their zooxanthellae (Symbiodinium)
}

\author{
JAMES DAVIS REIMER ${ }^{1}$, JULIEN LORION ${ }^{1}$, YUKA IREI ${ }^{1}$, BERT W. HOEKSEMA ${ }^{2}$ AND PETER WIRTZ $^{3}$ \\ ${ }^{1}$ Molecular Invertebrate Systematics and Ecology Laboratory, Graduate School of Engineering and Science, University of the \\ Ryukyus, Senbaru 1, Nishihara, Okinawa 903-0213, Japan, ${ }^{2}$ Department of Marine Zoology, Naturalis Biodiversity Center, PO Box \\ 9517, 2300 RA Leiden, The Netherlands, ${ }^{3}$ Centro de Ciências do Mar, Universidade do Algarve, P-80oo-117, Faro, Portugal
}

\begin{abstract}
This is the first report on the Zoantharia fauna (Cnidaria: Hexacorallia) of the isolated oceanic island of Ascension, southern Atlantic, where zoantharians are a dominant component of the shallow-water benthos. Specimens from two expeditions $(1983,2012)$ were examined regarding external morphology and molecular phylogeny using three DNA markers, which confirmed the presence of four zoantharian species: Palythoa caribaeorum; Palythoa aff. clavata; Parazoanthus swiftii; and Zoanthus sp. Two of these, Palythoa aff. clavata and Parazoanthus swiftii, were previously only known from the western Atlantic and Caribbean. Molecular examination of the zooxanthellae (=Symbiodinium spp.) of Palythoa specimens showed that they were in association with only one type, subclade $C_{1}$.
\end{abstract}

Keywords: Ascension Island, Atlantic, benthos, isolation, Palythoa, Parazoanthus, Symbiodinium, Zoantharia, zoogeography

Submitted 9 November 2013; accepted 10 April 2014; first published online 9 June 2014

\section{INTRDDUCTION}

Zoantharians are an order of Hexacorallia (Cnidaria: Anthozoa: Zoantharia) found in many marine environments, and possibly one of the most basal cnidarian groups (Kayal et al., 2013). In particular, the suborder Brachycnemina is common in shallow subtropical and tropical waters (Karlson, 1980; Swain, 2009; Irei et al., 2011), and most species in this group are zooxanthellate (i.e. contain symbiotic unicellular algae of the genus Symbodinium). Zoantharian taxonomy has been hindered by a combination of various factors, including but not limited to: a lack of clear diagnostic morphological characteristics (Burnett et al., 1997); high levels of intraspecific variation (Burnett et al., 1997; Reimer et al., 2004; Ong et al., 2013); and difficulties in conducting histological examinations due to the uptake of sand/detritus in the body wall of most species (Reimer et al., 2010b). Consequently, there are undoubtedly many synonyms in the literature, and the actual diversity of shallow water zoantharians, particularly in the zooxanthellate genera Palythoa and Zoanthus, may be considerably lower than previously thought (Burnett et al., 1997; Reimer et al., 2004, 2012a).

Over the last two decades, the utilization of molecular techniques has allowed researchers to re-examine zoantharian taxa, and while our understanding of the group is far from complete, the taxonomy of supraspecific levels probably reflects the evolutionary phylogeny of this order (Sinniger

Corresponding author:

J.D. Reimer

Email: jreimer@sci.u-ryukyu.ac.jp et al., 2010). Undoubtedly there are still many more species to be described (e.g. Reimer et al., 2012b; Sinniger et al., 2013), and some of a dubious nature to be combined (e.g. Hibino et al., 2014), but as progress is made on the understanding of zoantharian species diversity, research can begin to focus on answering ecological and biogeographical questions for this group.

Although there are many regions with little information, it appears that some brachycnemic zoantharian species are very widely distributed (e.g. Reimer et al., 2008; Hibino et al., 2014), and this may be due to their long planktonic larval stage (up to $190 \mathrm{~d}$; Polak et al., 2011). All subtropical and tropical islands of the world specifically investigated thus far have zoantharians present. Similar results are found from plankton net trawls; zoantharian larvae were present in all trawls in waters above $20^{\circ} \mathrm{C}$, regardless of the location or relative isolation of the trawl (Ryland et al., 2000). These data suggest that some zoantharian species are highly dispersive and widespread.

One of the most isolated islands is Ascension Island in the southern equatorial eastern Atlantic. It lies at $07^{\circ} 57^{\prime} \mathrm{S}$ $14^{\circ} 22 \mathrm{~W}$. The nearest land, St Helena Island, is about $1200 \mathrm{~km}$ south-east of it. The distance to Brazil is about $2300 \mathrm{~km}$ and the distance to West Africa about $1500 \mathrm{~km}$.

Zoantharians have previously been reported from Ascension Island (Irving, 1989, 2013; Manning \& Chace, 1990; Den Hartog \& Türkay, 1991), although the identifications are often only as 'zoanthid' or to genus level. Furthermore, 'Palythoa sp.' has been reported to be the dominant benthos in many areas on Ascension Island (Irving, 1989, 2013), which has been suggested to be one of the reasons why this island has a depauperate scleractinian coral fauna (Irving, 2013). When Den Hartog (1989a) visited 
Ascension on his way to St Helena in 1983 , he specifically reported on actiniarians that he collected in the rock pools of Shelly Beach but not on his collection of zoantharians, and neither on the corals that he sampled from here (see Hoeksema, 2012).

Research has shown that Ascension Island's shore-fish fauna is of eastern and western Atlantic origin, but is most closely related to that of Brazil (Lubbock, 1980; Briggs \& Bowen, 2012). However, as the species identifications of the dominant zoantharians of Ascension have not yet been clearly ascertained, the relationship between Ascension Island's benthos and other Atlantic regions remains less clear. Thus, in this study, we use previously reported DNA markers to ascertain the species identity of the zoantharians of Ascension Island by examining specimens collected during the SMSG/South Atlantic Environmental Research Institute (SAERI) expedition funded by the Darwin Initiative, supplemented with specimens from the Naturalis Biodiversity Center in Leiden, The Netherlands collected in 1983. We also examined endosymbiotic Symbiodinium spp. dinoflagellates of the zooxanthellate specimens by phylogenetic methods, as it has been demonstrated that there are often some levels of specificity between zoantharian hosts and their Symbiodinium type (Reimer et al., 2007b), and such data could also help infer the source of Ascension Island zoantharians.

\section{MATERIALS AND METHODS}

\section{Specimens}

Specimens from Ascension Island were collected from tide pools and by SCUBA diving in a depth range down to $25 \mathrm{~m}$. They were photographed in the field and preserved in $96 \%$ ethanol. New specimens have been deposited in the Coelenterata collection of the Naturalis Biodiversity Center (Leiden, The Netherlands) collection under specimen numbers RMNH Coel. RMNH $41606-\mathrm{RMNH} 41611$.

During research in 2012 at Naturalis Biodiversity Center by the first author, uncatalogued zoantharian specimens collected by J.C. den Hartog from Ascension Island in 1983 were examined and are included in this study.

\section{DNA extraction and PCR amplification}

DNA extraction was performed on specimens either utilizing a guanidine method as described in Sinniger et al. (2010) or by using a spin column Dneasy Blood \& Tissue Extraction kit following the manufacturer's instructions (Qiagen, Tokyo). PCR amplification using extracted genomic DNA was done using HotStarTaq Plus Master Mix Kit (Qiagen, Tokyo) following the manufacturer's instructions. Three zoantharian DNA markers were amplified in this study: mitochondrial $16 \mathrm{~S}$ ribosomal DNA (mt $16 \mathrm{~S}$ rDNA), cytochrome oxidase subunit I (COI), and the nuclear internal transcribed spacer region of ribosomal DNA (ITS-rDNA), with primers and amplification conditions as reported by Reimer et al. $(2007 \mathrm{a}, \mathrm{c})$ and Sinniger et al. (2010), respectively. The nuclear internal transcribed spacer region of ribosomal DNA (ITS-rDNA) of Symbiodinium spp. was additionally amplified in this study, using primers previously reported (White et al.,
1990; Rowan \& Powers, 1992; Hunter et al., 1997) and amplification conditions reported by Reimer et al. (2007b).

All amplified products were visualized by $1.0 \%$ agarose gel electrophoresis and positive products were treated with Shrimp Alkaline Phosphate (SAP; Takara) and Exonuclease I. Sequencing was performed by Fasmac (Kanagawa) on an $\mathrm{ABI}$ sequencer.

\section{Phylogenetic analyses}

Novel sequences obtained in this study were deposited in GenBank (Accession Numbers KJ794166-KJ794186). For mitochondrial COI and $16 \mathrm{~S}$-rDNA alignments, sequences of other zoantharian genera were incorporated into the alignment, while for zoantharian ITS-rDNA, two alignments of (1) only Palythoa spp. sequences, and (2) only Parazoanthidae sequences were generated due to high levels of divergence between sequences in other taxa. For all zoantharian alignments, sequences were aligned with previously reported DNA sequences from Atlantic zoantharians (Swain \& Wulff, 2007; Reimer et al., 2010a, 2012a). Novel Symbiodinium ITS-rDNA sequences (Table 1) were aligned with previously obtained clade C Symbiodinium sequences (see resulting phylogenetic tree), with a Symbiodinium clade F sequence as the outgroup.

The three zoantharian alignments ( $\mathrm{mt} 16 \mathrm{~S}$ rDNA + COI, Palythoa ITS-rDNA, Parazoanthidae ITS-rDNA) were constructed as mentioned in Reimer et al. (2012a), following previous alignments as guides. All alignments were inspected by eye and ambiguous sites (ambiguous or double peaks, $<_{2}$ sites/alignment) were removed prior to analyses. Three zoantharian alignment datasets were generated: (1) a concatenated $\mathrm{mt}$ 16S-rDNA + COI alignment with 44 sequences and 1060 sites; (2) a Palythoa ITS-rDNA alignment with 21 sequences and 909 sites; and (3) a Parazoanthidae ITS-rDNA alignment with 17 sequences and 955 sites. A Symbiodinium alignment of 318 sites of 20 sequences was additionally generated. All four alignments are available from the corresponding author upon request, and at the homepage www.miseryukyu.com.

The best-fitting model of nucleotide substitution was selected for each dataset using the corrected Akaike information criterion (AICc) in MrModeltest v.2 (Nylander, 2004) and Paup v4.ob1o (Swofford, 2000). Gene trees were inferred using the Bayesian method implemented in BEAST v.1.7.5 (Drummond \& Rambaut, 2007). A Yule speciation model was used as a tree prior and rate variation among lineages was modelled using an uncorrelated lognormal relaxed clock (Drummond et al., 2006), with the mean substitution rate fixed to 1 to get branch lengths in units of substitution per site. Posterior distributions of trees and parameters were estimated using Markov chain Monte Carlo (MCMC) sampling. Samples were drawn every 1000 steps over a total of 10 million MCMC steps. Each analysis was run four times, with mixing and convergence assessed using Tracer v.1.5. After discarding $10 \%$ of the samples as burn-in, samples from the four runs were thinned (sampling every 4000 steps) and pooled together. The maximum-cladecredibility tree was drawn from the pooled samples. Maximum likelihood (ML) trees were inferred using Treefinder (Jobb et al., 2004) for each dataset and their robustness was evaluated through bootstrapping (1000 replicates). 


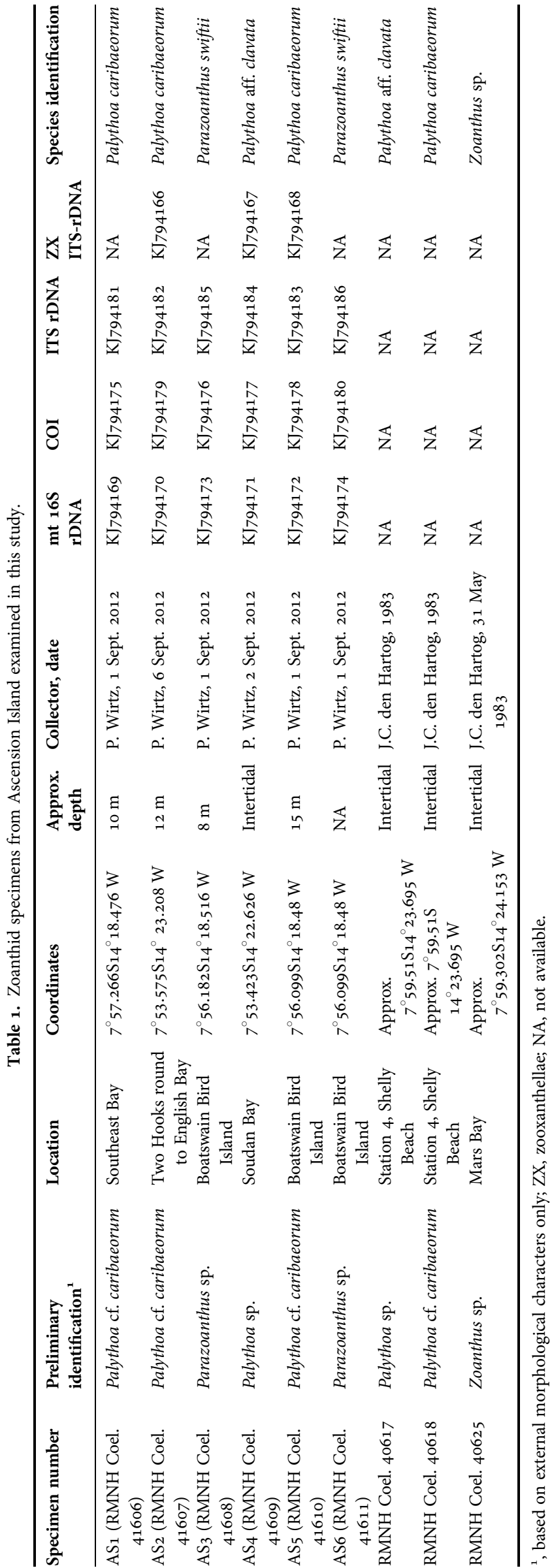

\section{RESULTS}

\section{Field collection}

During the SMSG/South Atlantic Environmental Research Institute (SAERI) expedition in 2012, six zoantharian specimens were collected from Ascension Island, belonging to three morphospecies (Table 1; Figure 1).

Two of these were zooxanthellate, heavily sand-encrusted Palythoa spp. One of them ( $\mathrm{N}=3$ specimens) was 'immersae' (Pax, 1910), with polyps embedded within a very well developed coenenchyme (Figure 1A). This morphospecies matched closely with Palythoa caribaeorum (Duchassaing \& Michelotti, 1860), and was preliminarily designated as Palythoa cf. caribaeorum. This morphospecies locally dominated the benthos around the island, from shallow water down to at least $15 \mathrm{~m}$ depth, forming colonies that could reach a size of more than $1 \mathrm{~m}^{2}$. Colony colour varied from light grey to dark brown.

The second Palythoa morphospecies was much more 'liberae' (Pax, 1910), with large polyps free and clear of the coenenchyme, and was preliminarily designated as Palythoa sp. (Figure 1B). Palythoa sp. was found in a tide pool at Soudan Bay.

The third species was designated as Parazoanthus sp. (Figure $1 \mathrm{C}$ ). It was common on overhanging walls and at cave entrances from about $5 \mathrm{~m}$ to at least $15 \mathrm{~m}$ depth, and was bright yellow in colour.

In the Naturalis Biodiversity Center coelenterate collection (RMNH Coel.), an additional three zoantharian specimens belonging to three morphospecies were found (Table 1). Two of the specimens were collected from the intertidal regions of Shelly Beach (precise date unknown, 1983) by J.C. den Hartog (see also Van der Land, 2003), and matched with Palythoa cf. caribaeorum and Palythoa sp., respectively (Table 1). Den Hartog visited Ascension Island for two days (31 May-1 June 1983) on the way from the United
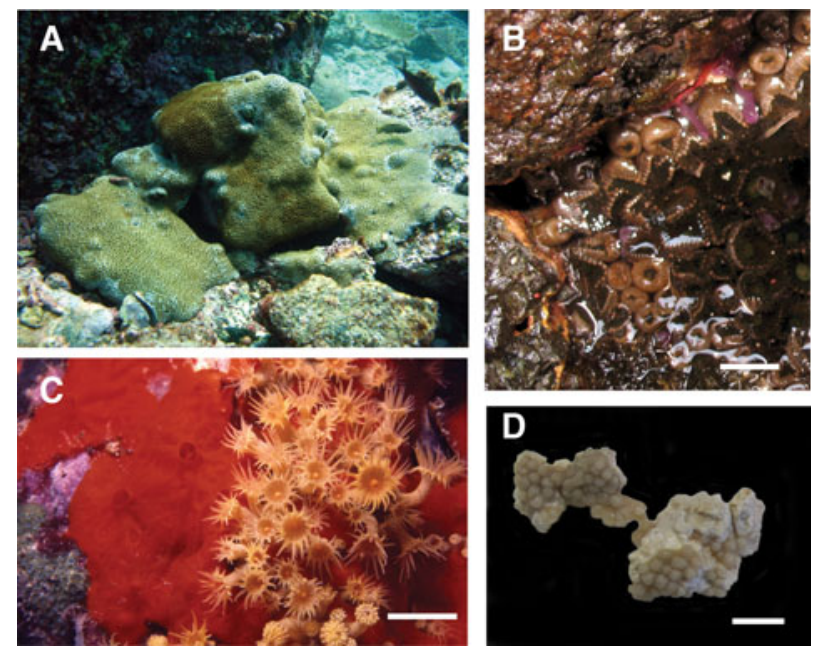

Fig. 1. Zoantharian species from Ascension Island as confirmed by morphological and phylogenetic results: (A) Palythoa caribaeorum (specimen AS2) at English Bay, which was a dominant component of the benthos at many sites around the island; (B) Palythoa aff. clavata (specimen AS4) from a tidal pool at Soudan Bay; (C) Parazoanthus swiftii (specimen $\mathrm{AS}_{3}$ ) at Boatswain Bird Island; (D) Zoanthus sp. specimen (RMNH Coel. 40625) from the Naturalis Biodiversity Center collection, collected from a tidepool at Mars Bay. Scale bars, $B-D \approx 1 \mathrm{~cm}$. 
Kingdom to St Helena onboard the MV 'Centaur' (Den Hartog, 1989a). The zoantharians could have been collected on 1 June 1983 , because on this date Den Hartog sampled corals from Shelly Beach (Hoeksema, 2012). The third specimen was from an exposed tide pool at Mars Bay (31 May 1983, J.C. den Hartog), and had been determined as Zoanthus sp. due to being zooxanthellate, with smooth polyps, and no sand encrustation (Figure 1D). In this study, we kept the Zoanthus sp. designation for this specimen.

\section{Phylogenetic analyses}

DNA was successfully amplified from all six newly collected specimens for all markers, but could not be amplified from the older Naturalis specimens, which were initially preserved in formalin.

\section{Zoantharian mt 16S-rDNA + COI tree}

In the mt $16 \mathrm{~S}-\mathrm{rDNA}+\mathrm{COI}$ tree created from zoantharian sequences, sequences from specimens $\mathrm{AS}_{1}, \mathrm{AS}_{2}$ and $\mathrm{AS}_{5}$ fell within a well-supported clade (PP: 0.98) consisting of previously reported Palythoa tuberculosa (Pacific), P. caribaeorum (Atlantic) and P. mutuki (Pacific) sequences (Figure 2). The concatenated sequences for $\mathrm{AS}_{4}$ fell within a grouping that included previously reported Palythoa aff. clavata sensu Reimer et al. (2012a) (Florida) sequences and Palythoa sp. 'sakurajimenis' (Japan) sequences. Sequences from a specimen from the Cape Verde Islands (Palythoa sp. 265 sensu Reimer et al. 2010a) were basal to this group.

Within Parazoanthidae, sequences from specimens $\mathrm{AS}_{3}$ and AS6 were within a well supported clade (PP: 0.93) that also contained previously reported sequences from Parazoanthus swiftii Haddon \& Shackleton, 1891 from the Caribbean and Parazoanthus sp. 1401 from the Cape Verde Islands.

\section{Zoantharian ITS-rDNA trees}

In the Palythoa ITS-rDNA tree, sequences from AS1, $\mathrm{AS}_{2}$ and $\mathrm{AS}_{5}$ were within a well supported $P$. caribaeorum/P. tuberculosa clade (PP: 0.99), closely related to but distinct from a

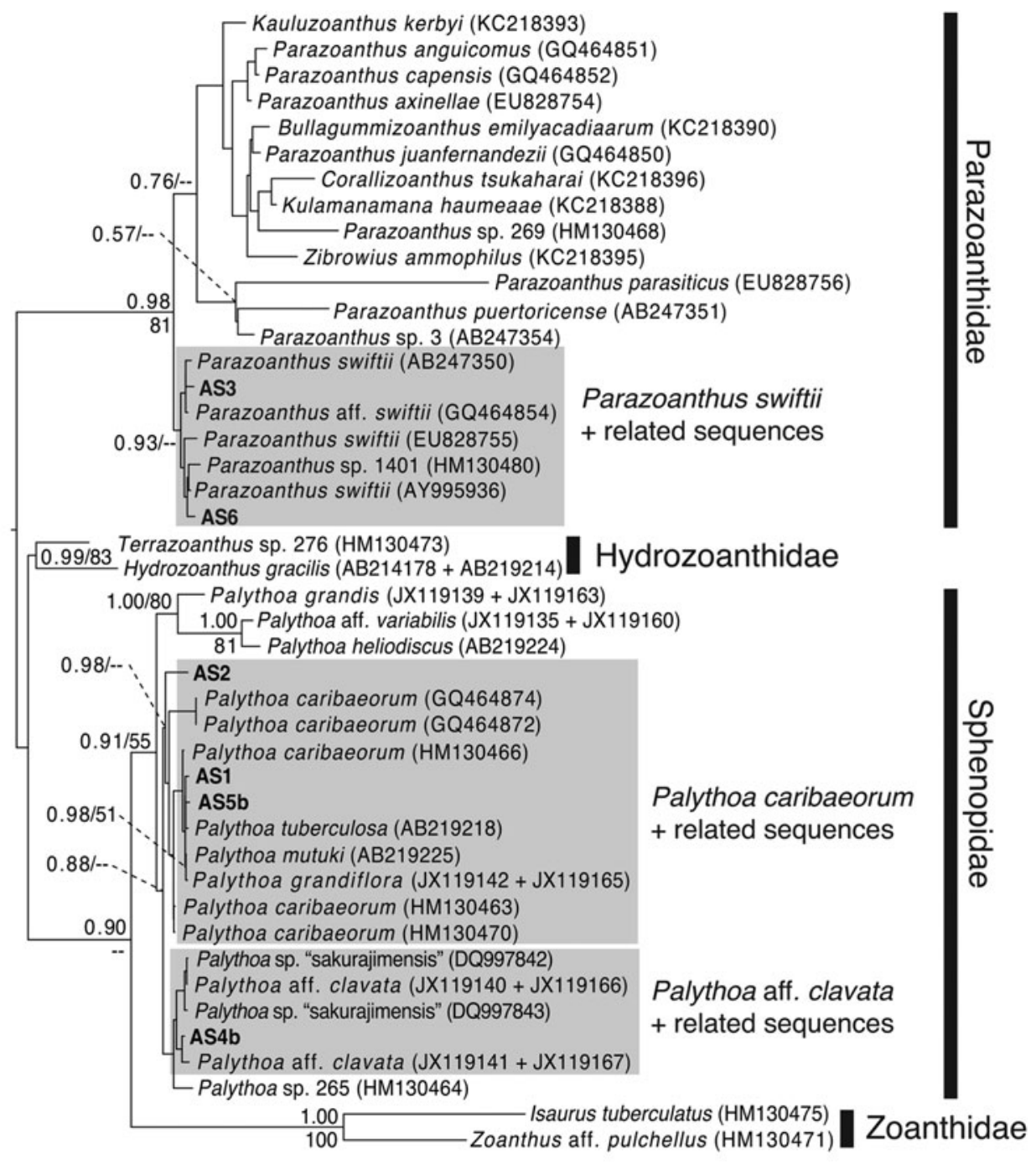

0.0050 substitutions/site

Fig. 2. Maximum-clade-credibility Bayesian tree obtained from the mitochondrial $16 \mathrm{~S}$ ribosomal DNA + cytochrome oxidase subunit I concatenated dataset. Posterior probabilities and percentages of bootstrap support obtained from the corresponding maximum likelihood analysis are given at nodes while above 0.50 and $50 \%$, respectively. Light grey boxes highlight high-level taxa discussed in the text. Novel sequences from this study in with specimen number (see Table 1 ) in bold. 
P. mutuki/P. grandiflora clade (Figure $3 \mathrm{~A}$ ). The sequence from $\mathrm{AS}_{4}$ was within a Palythoa aff. clavata clade (from Florida), distinct from Palythoa sp. 'sakurajimensis'.

In the Parazoanthus ITS-rDNA tree, sequences from $\mathrm{AS}_{3}$ and AS6 were within a well supported P. swiftii clade (PP: 0.83 ), distinct from other species' sequences (Figure $3 \mathrm{~B}$ ).

\section{Symbiodinium ITS-rDNA tree}

Symbiodinium ITS-rDNA sequences were successfully amplified for three of four specimens ( $\mathrm{AS}_{2}, \mathrm{AS}_{4}$ and $\left.\mathrm{AS}_{5}\right)$. All three sequences were identical over the ITS2 region with previously reported Symbiodinium clade C1 (GenBank Accession
Number EU074885) sensu LaJeunesse (2002) as well as Symbiodinium reported previously from some other zoantharian hosts in Japan (e.g. from Isaurus tuberculatus Gray, 1828 and Palythoa tuberculosa (Esper, 1791)) (Figure 4), and slightly different from previously reported Symbiodinium within zoantharians from the Cape Verde Islands.

\section{Specimen identities}

Based on the molecular results combined with external morphology, the Ascension specimens were identified as: Palythoa aff. clavata (AS4); Palythoa caribaeorum (AS1, AS2 and $\mathrm{AS}_{5}$ ); and Parazoanthus swiftii ( $\mathrm{AS}_{3}$ and AS6). The

A

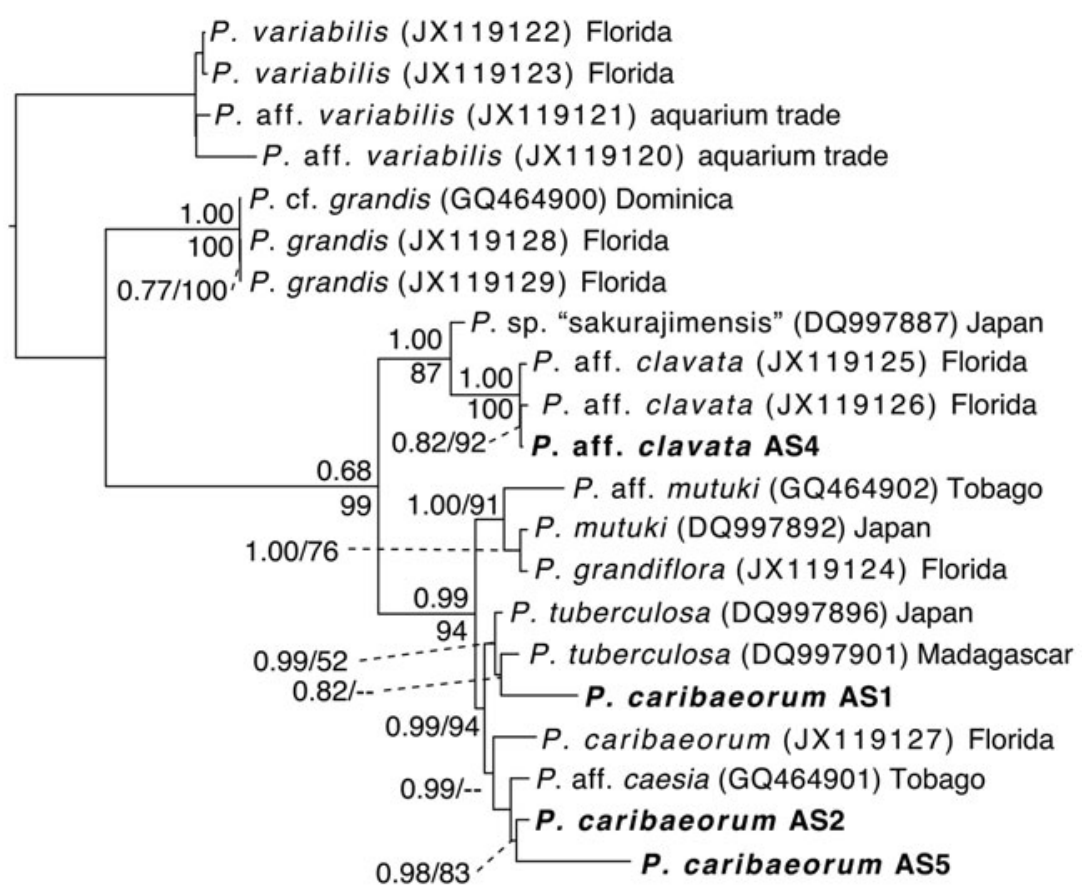

- 0.08 substitutions/site

B

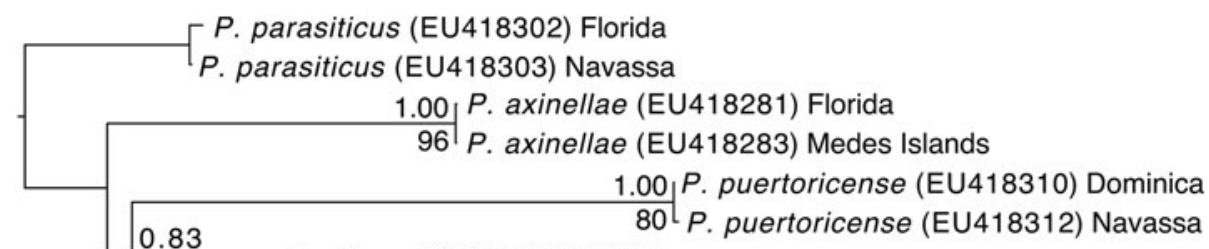

$57-174[P$. aff. swiftii (GQ464883) Peru

--174 P. swiftii (EU418326) Florida

$0.83 / 85 \mid P$. swiftii (EU418338) US Virgin Islands

$0.97 / 84$ P. swiftii (EU418320) Curaçao

$0.71 / 66,-1 P$. swiftii AS3

P. swiftii (EU418324) Florida

P. swiftii AS6

P. swiftii (EU418336) Tobago

P. swiftii (EU418337) Tobago

P. swiftii (EU418315) Barbados

0.05 substitutions/site

Fig. 3. Maximum-clade-credibility Bayesian trees obtained from the Palythoa (A) and parazoanthid (B) internal transcribed spacer region of ribosomal DNA (ITS-rDNA) datasets. Posterior probabilities and percentages of bootstrap support obtained from the corresponding maximum likelihood analysis are given at nodes while above 0.50 and $50 \%$, respectively. Geographical locations of specimens are given. Novel sequences from this study in with specimen number (see Table 1 ) in bold. 


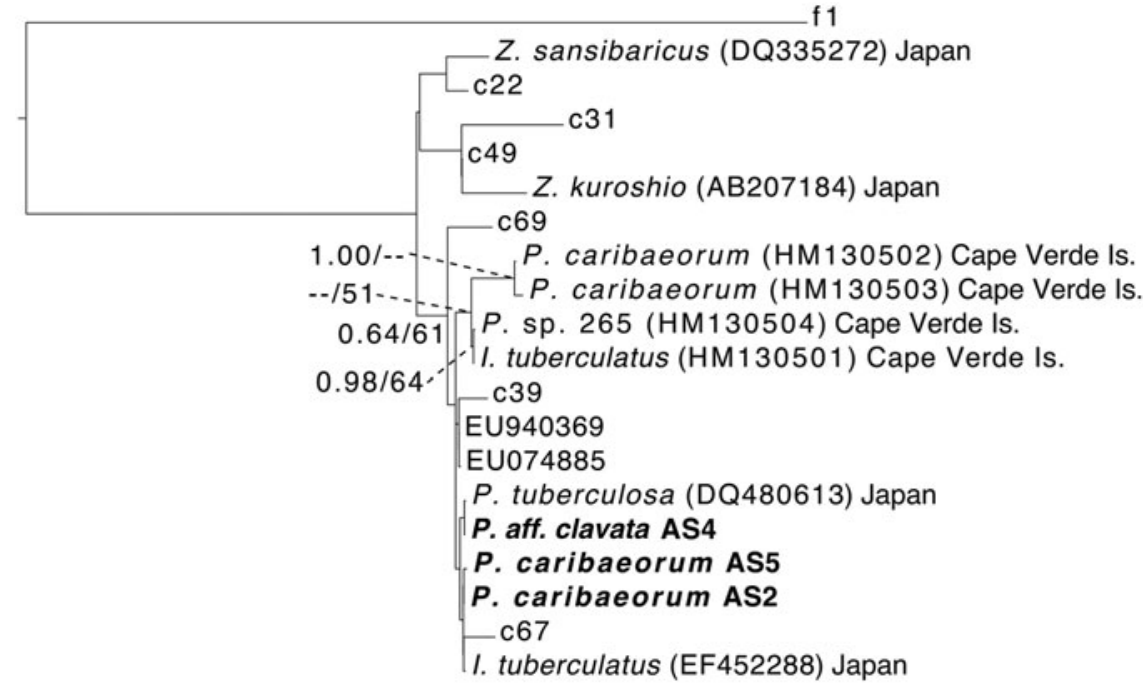

0.02

Fig. 4. Maximum-clade-credibility Bayesian tree obtained from the Symbiodinium internal transcribed spacer 2 (ITS2) dataset. Posterior probabilities and percentages of bootstrap support obtained from the corresponding maximum likelihood analysis are given at nodes while above 0.50 and $50 \%$, respectively. Geographical locations of host zoantharian specimens are given. Novel sequences from this study in with specimen number (see Table 1) in bold.

specimens from the Naturalis Biodiversity Center were identified as: Palythoa aff. clavata (RMNH Coel. 40617); P. caribaeorum (RMNH Coel. 40618); and Zoanthus sp. (RMNH Coel. 40625) (Table 1).

\section{DISCUSSIDN}

Previously, very few records of zoantharians existed for Ascension Island. Irving (1989) reported Parazoanthus swiftii from many sites at 'shaded areas under overhangs and in cliffs', and '?Palythoa sp.' on shallow upward facing surfaces around Boatswain Bird Island and Boatswain Bird Rock. The subsequent report by Irving (2013) again mentions $P$. swiftii as present at numerous locations, and 'Palythoa sp.' from Boatswain Bird Rock and Spire Rock. Additionally, one image of a massive Palythoa sp. colony appears, and this 'immersae' colony corresponds well with $P$. caribaeorum as identified in our study. Manning \& Chase (1990) reported on the presence of the crab Platypodiella picta (A. Milne Edwards, 1869) on Ascension Island. They mention that this crab lives in association with zoantharians as reported by Den Hartog \& Holthuis (1984) but did not mention that the latter refer to the Cape Verdes, thus only indirectly reporting the presence of zoantharians on Ascension Island.

The findings from field collection and subsequent molecular phylogenetic examination show that there are at least four zoantharian species present in the shallow waters of Ascension Island. Palythoa caribaeorum (corresponding to ?Palythoa sp. in Irving (1989), Palythoa sp. in Irving (2013), and Palythoa cf. caribaeorum as collected by den Hartog) is found extensively in sheets (Irving 2013) around the whole of Ascension Island. Surprisingly, Palythoa caribaeorum was not mentioned in an earlier report on Ascension Island's benthic communities (Price \& John, 1980). Palythoa aff. clavata (=Palythoa sp. as collected by den Hartog) was found so far only at Soudan Bay and at Shelly Beach. Parazoanthus swiftii (correctly identified by Irving $(1989,2013)$ was commonly found in shaded areas or caves. Finally, an unidentifiable
Zoanthus sp. was collected from Mars Bay by den Hartog in 1983, and was not found in 2012 surveys associated with this study. It may be that Zoanthus sp. is rare on Ascension Island. All in all, these results confirm the importance of historical museum collections as complementary and baseline material in faunistic studies based on recent surveys (Hoeksema et al., 2011; Hoeksema \& Wirtz, 2013).

The results of the phylogenetic analyses indicate that the zoantharian fauna of Ascension Island has affinities with the fauna of the western Atlantic and Caribbean. In particular, the finding of both Palythoa aff. clavata and Parazoanthus swiftii, species hitherto only reported from the Caribbean and western Atlantic, demonstrates this. Not only slower evolving mitochondrial DNA (Shearer et al., 2002) but also ITS-rDNA sequences from Ascension specimens unequivocally identify both these species. Furthermore, in a recent examination of zoantharians from the Cape Verde Islands in the north-eastern Atlantic (Reimer et al., 2010a), species with similar morphology (Palythoa sp. $265=$ perhaps $P$. canariensis Haddon \& Duerden, 1896; and Parazoanthus sp. 1401) had different COI or mt $16 \mathrm{~S}$ rDNA sequences than Palythoa aff. clavata and Parazoanthus swiftii (see Figures 2, 3 ), respectively. Thus, given slow mtDNA rates of change in zoantharians, such results indicate that the north-eastern Atlantic may harbour species different from both Ascension Island and the western Atlantic. However, before any final conclusions on the origins of zoantharians at Ascension can be made, more data are needed from the subtropical and tropical West African coastline. Regardless, our data show that molecular identification of zoantharians is perhaps the most accurate way to identify to species or species-group levels (Sinniger et al., 2008), particularly in genera such as Palythoa and Zoanthus in which there exists high levels of intraspecific variation (Burnett et al., 1997; Reimer et al., 2004).

The presence of four zoantharian species at such an extremely isolated island such as Ascension Island demonstrates how widely some zoantharian species are distributed. While this is not unexpected for brachycneminic Palythoa 
and Zoanthus based on past research showing such species with potentially long planktonic larval stages (Ryland et al., 2000; Hirose et al., 2011; Polak et al., 2011), the length of the larval stages of macrocneminic zoantharians such as Parazoanthus swiftii are relatively unknown (but see Ryland \& Westphalen, 2004), and our results here suggest that they too may have long-lived planktonic larval stages. Longdistance dispersal by rafting may be another explanation for widespread distributions in shallow-water benthic species, as demonstrated in a brooding scleractinian reef coral species (Hoeksema et al., 2012), but free-floating material appears to be almost entirely absent around Ascension Island (Price \& John, 1980).

If the zoantharians at Ascension Island are affiliated with the western Atlantic (e.g. Brazilian) fauna, it is open to speculation how these species reached Ascension Island, particularly given the presence of the South Equatorial Current flowing from east to west between $2^{\circ} \mathrm{N}$ and $2^{\circ} \mathrm{S}$. Den Hartog (1989b) remarked on similarities between the marine fauna of Ascension and St Helena with both the Mediterraneannorth-west African marine fauna and that of the Caribbean, which he also linked to the South Equatorial Current. There are two possible alternative explanations. One is that the Brazilian coast, despite being further away from Ascension Island, is much more speciose than the African coast, and therefore more species from the western Atlantic arrive at Ascension Island (e.g. Floeter et al., 2008). The other contributing factor is the Atlantic Equatorial Undercurrent, which flows from $3^{\circ} \mathrm{S}$ to $5^{\circ} \mathrm{S}$, runs from west to east at a depth of less than $100 \mathrm{~m}$, and has temperatures potentially warm enough $\left(>20^{\circ} \mathrm{C}\right.$, Ryland et al., 2000) to transport brachycneminic larvae to Ascension Island. This current has been suggested to be a factor in Ascension Island's fish fauna being more related to the Brazilian fauna as opposed to the African fauna (Briggs \& Bowen, 2012).

Brachycneminic zoantharians are known to thrive in disturbed environments (Sebens, 1982), and it may be that dominant Palythoa caribaoerum was among the first benthic species to arrive to the shallow Ascension waters. It is interesting to note that zoantharians have been reported from all tropical and subtropical areas where they have been looked for, indicating that they are effective shallow-water benthic colonizers. Future research into the diversity of the zoantharian fauna of the West African coast, as well as from other isolated oceanic island regions, should help to expand the findings of this study.

\section{ACKNDWLEDGEMENTS}

The funding for this work came from a grant to Dr Paul Brickle from the Darwin Initiative (EIDCFo12). We are grateful to the Shallow Marine Surveys Group and the South Atlantic Environmental Research Institute for organizing the expedition. We are also very grateful to the Ascension Island Government, the members of staff at the Conservation Centre and Ascension Island Dive Club for their cooperation, accommodation and hospitality. Finally we are grateful to British Forces South Atlantic Islands for their logistic support. Thanks to Stedson Stroud and Jolene Sim of the Ascension Conservation Department for their help during the expedition. The discussion was enhanced by input from Luiz Rocha (California Academy of Sciences) and Brian Bowen (University of Hawaii).

\section{FINANCIAL SUPPDRT}

Collections by P.W. were part of the SMSG/South Atlantic Environmental Research Institute (SAERI) expedition funded by the Darwin Initiative Challenge Fund Grant (EIDCFo12). J.D.R. was funded by a grant-in-aid from the Japan Society for the Promotion of Science ('Wakate B' \#217700896), as well as the Rising Star Program and International Research Hub Project for Climate Change and Coral Reef/Island Dynamics, both at the University of the Ryukyus. Additionally, examination of specimens at Naturalis was funded by a Temminck Fellowship Grant to J.D.R. from May to June 2012.

\section{REFERENCES}

Briggs J.C. and Bowen B.W. (2012) A realignment of marine biogeographic provinces with particular reference to fish distributions. Journal of Biogeography 39, 12-30.

Burnett W.J., Benzie J.A.H., Beardmore J.A. and Ryland J.S. (1997) Zoanthids (Anthozoa, Hexacorallia) from the Great Barrier Reef and Torres Strait, Australia: systematics, evolution and a key to species. Coral Reefs 16, 55-68.

Den Hartog J.C. (1989a) Herrineringen aan een reis naar Sint-Helena (1). Dieren 6, 48-53.

Den Hartog J.C. (1989b) Herrineringen aan een reis naar Sint-Helena (3). Dieren 6, 114-120.

Den Hartog J.C. and Holthuis L.B. (1984) A note on an interesting association of the crab Platypodiella picta (A. Milne Edwards 1869) and species of Zoantharia. Courier Forschungsinstitut Senckenberg 68, 21-29.

Den Hartog J.C. and Türkay M. (1991) Platypodiella georgei spec. nov. (Brachyura: Xanthidae), a new crab from the island of St. Helena, South Atlantic Ocean, with notes on the genus Platypodiella Guinot, 1967. Zoologische Mededelingen Leiden 65, 209-220.

Drummond A.J. and Rambaut A. (2007) BEAST: Bayesian evolutionary analysis by sampling trees. BMC Evolutionary Biology 7, 214.

Drummond A.J., Ho S.Y.W., Phillips M.J. and Rambaut A. (2006) Relaxed phylogenetics and dating with confidence. PLoS Biology 4, 699-710.

Floeter S.R., Rocha L.A., Robertson D.R., Joyeux J.C., Smith-Vaniz W.F., Wirtz P., Edwards A.J., Barreiros J.P., Ferreira C.E.L., Gasparini J.L., Brito A., Falcón J.M., Bowen B.W. and Bernardi G. (2008) Atlantic reef fish biogeography and evolution. Journal of Biogeography 35, 22-47.

Hibino Y., Todd P.A., Yang S.Y., Benayahu Y. and Reimer J.D. (2014) Molecular and morphological evidence for conspecificity of two common Indo-Pacific species of Palythoa (Cnidaria: Anthozoa). Hydrobiologia $733,31-43$.

Hirose M., Obuchi M., Hirose E. and Reimer J.D. (2011) Timing of spawning and early development of Palythoa tuberculosa (Anthozoa, Zoantharia, Sphenopidae) in Okinawa, Japan. Biological Bulletin. Marine Biological Laboratory, Woods Hole 220, 23-31.

Hoeksema B.W. (2012) Extreme morphological plasticity enables a free mode of life in Favia gravida at Ascension Island (South Atlantic). Marine Biodiversity 42, 289-295. 
Hoeksema B.W. and Wirtz P. (2013) Over 130 years of survival by a small, isolated population of Favia gravida corals at Ascension Island (South Atlantic). Coral Reefs 32, 551.

Hoeksema B.W., Van der Land J., Van der Meij S.E.T., Van Ofwegen L.P., Reijnen B.T., Van Soest R.W.M. and De Voogd N.J. (2011) Unforeseen importance of historical collections as baselines to determine biotic change of coral reefs: the Saba Bank case. Marine Ecology 32, 135-141.

Hoeksema B.W., Roos P.J. and Cadée G.C. (2012) Trans-Atlantic rafting by the brooding reef coral Favia fragum on man-made flotsam. Marine Ecology Progress Series 445, 209-218.

Hunter C.L., Morden C.W. and Smith C.M. (1997) The utility of ITS sequences in assessing relationships among zooxanthellae and corals. Proceedings of the 8th International Coral Reef Symposium 2, 15991602.

Irei Y., Nozawa Y. and Reimer JD. (2011) Distribution patterns of five zoanthid species in Okinawa Island, Japan. Zoological Studies 50, $426-433$.

Irving R. (2013) Ascension Island's hermatypic but non-reef building corals. In Sheppard C.R.C. (ed.) Coral reefs of the United Kingdom overseas territories-Coral reefs of the world, Springer Science and Business Media Dordrecht, Volume 4, pp. 213-221.

Jobb G., von Haeseler A. and Strimmer K. (2004) TREEFINDER: a powerful graphical analysis environment for molecular phylogenetics. BMC Evolutionary Biology 4, 18.

Karlson R.H. (1980) Alternative competitive strategies in a periodically disturbed habitat. Bulletin of Marine Science 30, 894-900.

Kayal E., Roure B., Philippe H., Collins A.G. and Lavrov D.V. (2013) Cnidarian phylogenetic relationships as revealed by mitogenomics. $B M C$ Evolutionary Biology 13, 5 .

LaJeunesse T.C. (2002) Diversity and community structure of symbiotic dinoflagellates from Caribbean coral reefs. Marine Biology 141, 387400 .

Lubbock R. (1980) The shore fishes of Ascension Island. Journal of Fish Biology 17, 283-303.

Manning R.B. and Chace Jr F.A. (1990) Decapod and stomatopod Crustacea from Ascension Island, South Atlantic Ocean Smithsonian Contributions to Zoology 503, 1-91.

Nylander J.A.A. (2004) MrModeltest v2. Program distributed by the author. Evolutionary Biology Centre, Uppsala University, Uppsala Sweden.

Ong D.C.W., Reimer J.D. and Todd P.A. (2013) Morphologically plastic responses to shading in the zoanthids Zoanthus sansibaricus and Palythoa tuberculosa. Marine Biology 160, 1053-1064.

Pax F. (1910) Studien an westindischen Actinien. Zoologische Jahrbücher Supplement 11, 157-330.

Polak O., Loya Y., Brickner I., Kramarski-Winter E. and Benayahu Y. (2011) The widely-distributed Indo-Pacific zoanthid Palythoa tuberculosa: a sexually conservative strategist. Bulletin of Marine Science 87, 605-621.

Price H. and John D.M. (1980) Ascension Island, south Atlantic: a survey of inshore benthic macroorganisms, communities and interactions. Aquatic Botany 9, 251-278.

Reimer J.D., Ono S., Fujiwara Y., Takishita K. and Tsukahara J. (2004) Reconsidering Zoanthus spp. diversity: molecular evidence of conspecificity within four previously presumed species. Zoological Science 21, 517-525.

Reimer J.D., Hirano S., Fujiwara Y., Sinniger F. and Maruyama T. (2007a) Morphological and molecular characterization of Abyssoanthus nankaiensis, a new family, new genus and new species of deep-sea zoanthid (Anthozoa: Hexacorallia: Zoantharia) from a northwest Pacific methane cold seep. Invertebrate Systematics 21, $255-262$.

Reimer J.D., Ono S., Tsukahara J., Takishita K. and Maruyama T. (2007b) Non-seasonal clade-specificity and subclade microvariation in symbiotic dinoflagellates (Symbiodinium spp.) in Zoanthus sansibaricus (Anthozoa: Hexacorallia) at Kagoshima Bay, Japan. Phycological Research 55, 58-65.

Reimer J.D., Takishita K., Ono S. and Maruyama T. (2007c) Diversity and evolution in the zoanthid genus Palythoa (Cnidaria: Hexacorallia) utilizing nuclear ITS-rDNA. Coral Reefs 26, 399-410.

Reimer J.D., Hirose M. and Wirtz P. (2010a) Zoanthids of the Cape Verde Islands and their symbionts: previously unexamined diversity in the Northeastern Atlantic. Contributions to Zoology 79, 147-163.

Reimer J.D., Nakachi S., Hirose M., Hirose E. and Hashiguchi S. (2010b) Using hydrofluoric acid for morphological investigations of zoanthids (Cnidaria: Anthozoa): a critical assessment of methodology and necessity. Marine Biotechnology 12, 605-617.

Reimer J.D., Foord C. and Irei Y. (2012a) Species diversity of shallow water zoanthids (Cnidaria: Anthozoa: Hexacorallia) in Florida. Journal of Marine Biology Article ID 856079. doi: 10.1155/2012/ 856079 .

Reimer J.D., Irei Y. and Fujii T. (2012b) Two new species of Neozoanthus (Cnidaria, Hexacorallia, Zoantharia) from the Pacific. ZooKeys 246, 69-87.

Rowan R. and Powers D.A. (1992) Ribosomal RNA sequences and the diversity of symbiotic dinoflagellates (zooxanthellae). Proceedings of the National Academy of Sciences of the United States of America 89, 3639-3643.

Ryland J.S. and Westphalen D. (2004) The reproductive biology of Parazoanthus parasiticus (Hexacorallia: Zoanthidea) in Bermuda. In Fautin D.G., Westfall J.A., Cartwright P., Daly M. and Wyttenbach C.R. (eds) Coelenterate biology 2003: trends in research on Cnidaria and Ctenophora. Hydrobiologia, 530/531, 411-419.

Ryland J.S., de Putron S., Scheltema R.S., Chimonides R.S. and Zhadan D.G. (2000) Semper's (zoanthid) larvae: pelagic life, parentage and other problems. Hydrobiologia 440, 191-198.

Sebens K.P. (1982) Intertidal distribution of zoanthids on the Caribbean coast of Panama: effects of predation and desiccation. Bulletin of Marine Science 32, 316-335.

Shearer T.L., van Oppen M.J.H., Romano S.L. and Wörheide G. (2002) Slow mitochondrial DNA sequence evolution in the Anthozoa (Cnidaria). Molecular Ecology 11, 2475-2487.

Sinniger F., Reimer J.D. and Pawlowski J. (2008) Potential of DNA sequences to identify zoanthids (Cnidaria: Zoantharia). Zoological Science 25, 1253-1260.

Sinniger F., Reimer J.D. and Pawlowski J. (2010) The Parazoanthidae DNA taxonomy: description of two new genera. Marine Biodiversity $40,57-70$

Sinniger F., Ocaña O.V. and Baco A.R. (2013) Diversity of zoanthids (Anthozoa: Hexacorallia) on Hawaiian seamounts: description of the Hawaiian gold coral and additional zoanthids. PLoS One 8, e52607. doi: 10.1371/journal.pone.0052607

Swain T.D. (2009) Phylogeny-based species delimitations and the evolution of host associations in symbiotic zoanthids (Anthozoa, Zoanthidea) of the wider Caribbean region. Zoological Journal of the Linnean Society 156, 223-238.

Swain T.D. and Wulff J.L. (2007) Diversity and specificity of Caribbean sponge-zoanthid symbioses: a foundation for understanding the adaptive significance of symbioses and generating hypotheses about 
higher-order systematics. Biological Journal of the Linnean Society 92, 695-711.

Swofford D.L. (2000) PAUP*. Phylogenetic analysis using Parsimony ( ${ }^{*}$ and other methods). Version 4. Sunderland, MA: Sinauer Associates.

Van der Land J. (2003) In memoriam Jacobus Cornelis (Koos) den Hartog (1942-2000), marine naturalist. Zoologische Verhandelingen Leiden 345, 9-17.

and

White T.J., Bruns T., Lee S. and Taylor W.J. (1990) Amplification and direct sequencing of fungal ribosomal genes for phylogenetics. In
Innis M.A., Gelfanfd D.H., Sninsky J.J. and White T.J. (eds) PCR protocols: a guide to methods and applications. San Diego, CA: Academic Press, pp. 315-322.

\section{Correspondence should be addressed to:}

J.D. Reimer

Molecular Invertebrate Systematics and Ecology Laboratory Graduate School of Engineering and Science, University of the Ryukyus, Senbaru 1, Nishihara, Okinawa 903-0213, Japan email: jreimer@sci.u-ryukyu.ac.jp 